\title{
Learning Asymmetries in Real Business Cycles
}

\author{
Stijn Van Nieuwerburgh*and Laura Veldkamp ${ }^{\dagger}$
}

July $3,2003^{\ddagger}$

\begin{abstract}
When an economic boom ends, the downturn is generally sharp and short. When growth resumes, the boom is more gradual. Our explanation for this pattern rests on learning about productivity. When agents believe productivity is high, they work, invest, and produce more. More production generates higher precision information. When the economy passes the peak of a productivity boom, precise estimates of the slowdown prompt quick, decisive reactions: Investment and labor fall sharply. At the end of a slump, low production yields noisy estimates of the recovery. The noise impedes learning, slows the recovery, and makes booms more gradual than crashes. A calibrated model generates asymmetry in growth rates similar to macroeconomic aggregates. Fluctuations in agents' forecast precision match observed countercyclical dispersion in analysts' macroeconomic forecasts.
\end{abstract}

"There is, however, another characteristic of what we call the trade cycle that our explanation must cover; namely, the phenomenon of the crisis - the fact that the substitution of a downward for an upward tendency often takes place suddenly and violently, whereas there is, as a rule, no such sharp turning point when an upward is substituted for a downward tendency." J.M. Keynes (1936)

\footnotetext{
${ }^{*}$ New York University, Stern School of Business, Department of Finance

${ }^{\dagger}$ Corresponding author: New York University, Stern School of Business, Department of Economics. lveldkam@stern.nyu.edu, 44 West 4th St., New York, NY 10012.

${ }^{\ddagger}$ First version: May 15, 2001. Many thanks to Tom Sargent, Tim Cogley, Paul Romer, Peter Henry, Bob Hall, Ken Judd, Pierre Weill, Hanno Lustig, John Shea, Tim Johnson, Robert Rich and attendees of the Stanford Macro Lunch, the 2002 meetings of the Econometric Society in Los Angeles and the economics seminar at the University of Leuven, Munich and Humbolt University for their helpful advice. Stijn Van Nieuwerburgh thanks SIEPR and the Flanders Fund for Scientific Research for financial support. All remaining errors are our own. JEL classification: E32, D83, E27. Keywords: learning, asymmetry, business cycles, uncertainty.
} 


\section{Introduction}

When an economic boom ends, the downturn is generally sharp and short, meaning that the growth rate falls far below trend for a short period of time. When a slump ends and growth resumes, the boom is more gradual: longer lasting, with growth rates not as far from trend. This type of asymmetry is referred to as "growth-rate" or "steepness" asymmetry. It is present in many macroeconomic aggregates: output, industrial production, fixed investment and hours worked. In the 1990-91 recession, investment fell by $7 \%$ and the unemployment rate rose by $1.8 \%$ points over the course of three quarters. The recovery in the first half of the nineties was much more gradual. Likewise, in the first three quarters of the 2001 recession, investment fell by $6.5 \%$ and the unemployment rate rose by $1.5 \%$ points. In spite of a reduction in the volatility of business cycles over the last two decades, their asymmetry has not diminished. In the decade from 1985 to 1995 , changes in monthly industrial production had a skewness of -0.6, compared to -0.2 in the decade before and -0.8 in the period $1945-75 .^{1}$

We explain this asymmetry with an endogenously varying rate of information flow about the aggregate technology. When productivity is high, agents work harder and invest more. More production generates higher-precision information about the level of technology, which is unobservable. When the economy passes the peak of a productivity boom, agents have precise estimates of the extent of the slowdown. Firms abruptly reduce investment projects and labor demand. At the end of a productivity slump, low levels of production yield noisy estimates about the extent of the recovery. This extra uncertainty at the start of an upturn restrains the expansion of investment projects and new hiring. This restraint delays the recovery and makes booms more gradual than crashes.

The model of asymmetric learning is embedded into a dynamic stochastic general equilibrium model. $^{2}$ Its distinguishing feature is the additive stochastic term in the output equation: $y_{t}=$ $z_{t} f_{t}+\eta_{t}$. Because the additive noise term $\eta$ and the aggregate technology level $z$ are unobserved, agents use observed capital and labor inputs, $f_{t}=f\left(k_{t}, n_{t}\right)$, and output $y_{t}$ to form Bayesian beliefs

\footnotetext{
${ }^{1}$ Negative skewness in the distribution of changes captures the presence of slow increases, a large number of small, positive changes, and sudden decreases, a small number of large negative changes.

${ }^{2}$ See Kydland and Prescott (1982), Cooley and Prescott (1995), and Backus, Kehoe and Kydland (1992).
} 
about technology. Since technology is multiplied by a function of inputs, larger inputs amplify changes in technology. Higher variance in technology relative to noise makes technology more easily observable. Following a change in technology, the speed of learning measures how quickly beliefs converge to the truth. When the economy is in recession and inputs are low, filtered estimates of technology are imprecise and learning is slow. In a boom, high capital and labor utilization make learning faster. This variation in the speed of learning over the business cycle produces the asymmetry in growth rates.

One interpretation of the additive noise term is as the contribution of intangibles to output. This contribution is stochastic with a distribution that is invariant over the business cycle. Examples at the level of the firm of such fixed factors are the (non-labor and non-capital components of) senior management, branding \& marketing, or research \& development. Section 4 explores this interpretation and its implications.

A key feature of our explanation for asymmetry is that recessions are times of high uncertainty. Evidence from the Survey of Professional Forecasters supports this prediction. The median forecast error and the dispersion of the GDP forecast across a panel of forecasters goes up in recessions. This is evidence of more uncertainty about the state of the business cycle in recessions.

A calibration exercise shows that the model is able to replicate the negative skewness of output, investment, employment and consumption. The model matches not only the magnitude of asymmetry but also its frequency pattern. Skewness in output changes is a high frequency phenomenon. It decreases as the length of the period over which changes are computed increases. It disappears for 3-4 year changes. The model replicates this pattern because short term uncertainty about the current state is resolved after a few periods.

Understanding the source of business cycle asymmetry improves forecasting of macroeconomic aggregates. Acemoglu and Scott (1997) estimate that allowing for asymmetric booms and crashes captures an additional $12 \%$ of US output growth fluctuations. Neftci (1984) shows that Federal Reserve Board estimates of employment perform significantly worse at business cycle turning points because they do not capture the asymmetric nature of booms and crashes. An individual in our model, who behaves as though learning were symmetric, incurs a $4 \%$ higher cost of business cycles 
than agents who understand learning asymmetries. To the extent that there are gains from reducing business cycle fluctuations, this result suggests non-trivial benefits from understanding the source of asymmetry.

\section{Literature on Asymmetry and Learning}

The literature on business cycle asymmetries measures and models many different types of asymmetry. Most asymmetries fall into three categories: level asymmetries (deepness), growth rate asymmetries (steepness) and delays. All three are distinct features of the data. Level asymmetry refers to the unconditional distribution of detrended output levels, whereas growth rate asymmetry refers to the unconditional distribution of output changes. Growth rate asymmetry means that increases and decreases in output have different distributions. Delay asymmetry results when the output level stagnates at the trough of an otherwise symmetric cycle. Figure 1 illustrates the shape of the cycle produced by level, growth rate and delay asymmetries.
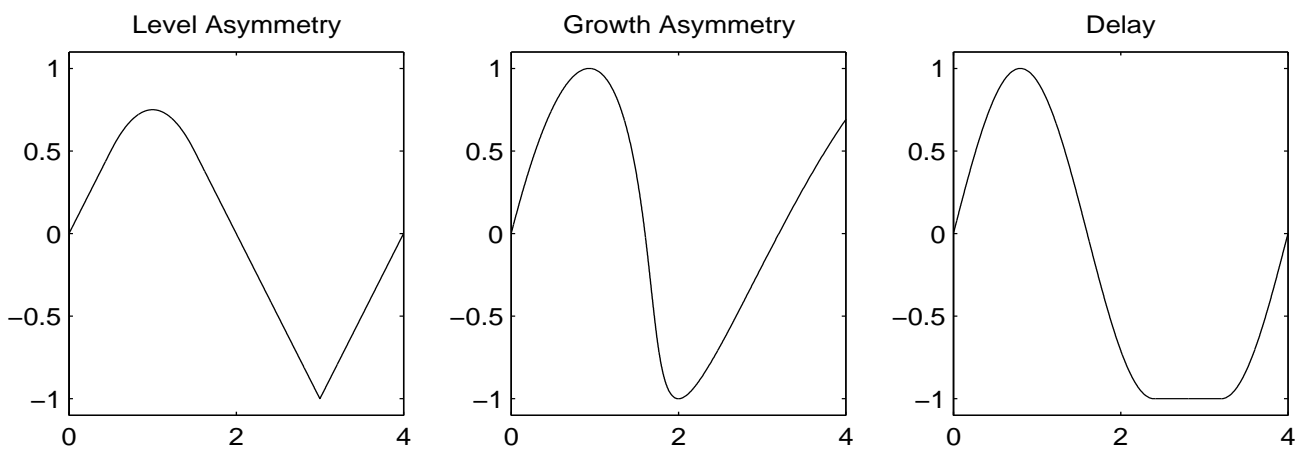

Previous papers have used a variety of mechanisms to produce business cycle asymmetries. Hansen and Prescott (2000) use capacity constraints to prevent booms from being as large a deviation from trend as recessions. In contrast, Kocherlakota (2000) and Acemoglu and Scott (1997) use credit constraints and learning-by-doing to amplify shocks in the trough of a business cycle. Williams (2002) uses large deviation theory to investigate asymmetries in the probability of large recessions and booms. These are examples of level asymmetry.

Most explanations for growth rate asymmetry rely in some way on a learning process. In a 
partial equilibrium model of lending, Veldkamp (2001) uses the idea of faster learning when more investment projects are undertaken to generate asymmetry in investment and interest rates. Using a varying signal quality rather than a varying number of signals makes more precise calibration in this paper possible. Chakley and Lee (1998) employ noise traders who become a relatively larger fraction of the market in bad times. Boldrin and Levine (2001)'s asymmetric spread of new technologies, Jovanovic (2003)'s asymmetric technology adoption costs, and Zeira (1999)'s learning about market capacity, all have bad signals that are either more informative or more extreme than good signals.

Chamley and Gale (1994) generate delay asymmetry using irreversible investment. Their model shares the feature that investment generates information. At low levels of production, firms wait to produce until they have learned from other firms' investments. This produces the delayed recovery that the authors aim to explain. Since delay is neither an upturn nor a downturn it will not affect the relative speed of booms and crashes.

Our explanation for growth asymmetry relies on the fact that recessions are times when uncertainty is high. This relationship is a recurrent idea in economics. In a model with a GARCH shock to output, a sudden downturn increases expected future output volatility (Ebell (2001)). To guard against consumption disasters, risk-averse agents scale back their inputs, accentuating the downturn when uncertainty is high. This paper generates GARCH-like dynamics endogenously through the learning mechanism. Potter (1999) claims that recessions are caused by uncertainty about the economic environment which makes firms unable to coordinate on a high-output equilibrium. Estimating a Bayesian model where agents are learning about the growth rate, Cogley (2002) finds that consumers may have more difficulty determining the permanent component of their income when output is low.

Work from many corners of economics suggests that learning and output fluctuations are intimately related: learning by doing (Jovanic and Nyarko (1982)), learning by lending (Lang and Nakamura (1990)), learning about demand (Rob (1991)). Within the business cycle literature, Cagetti, Hansen, Sargent and Williams (2001) have agents who are uncertain about the drift of technology and solve a filtering problem, as in this model. Evans, Honkapohja and Romer (1998) 
and Kasa (1995) show that business cycles can be produced by learning, rather than by technological fluctuations. In these models, learning is not only related to the business cycle, it is fundamental to the cyclical behavior.

\section{Evidence of Business Cycle Learning}

Before we show that our model is capable of producing asymmetry, we first ask whether learning is a plausible explanation for business cycle asymmetry. The theory relies on lower precision forecasts in bad times than in good. To test this hypothesis empirically, we measure the precision of analysts' forecasts of future real GDP.

To approximate the amount of uncertainty, we use the median forecast error in a panel of forecasters. For a given quarter, the median forecast error is the log absolute deviation of the median forecast from the final nominal GDP, where the latter is measured two quarters after the end of the quarter. Analysts forecast nominal GDP one through four quarters into the future. The hypothesis is that the median forecast error is negatively correlated with the detrended level of output.

Table 1 contains the results of regressions with detrended GDP as the independent variable and the median forecast error as the dependent variable. Detrending is done with a Hodrick and Prescott (1997) filter. The correlation between uncertainty and output is negative for all forecast horizons (1 to 4 quarters ahead) and increases in magnitude and significance with the forecast horizon. This supports the model's prediction that agents have larger GDP forecast errors (learning is slower) when output is low.

\begin{tabular}{||l|cccc||}
\hline Forecast Horizon & +1 & +2 & +3 & +4 \\
\hline Median Error & -0.00 & -0.11 & $-0.25^{* *}$ & $-0.33^{* *}$ \\
( t-stat) & $(0.07)$ & $(1.58)$ & $(3.65)$ & $(4.98)$ \\
\hline
\end{tabular}

Table 1: Dependent variable is the absolute value of the median analyst forecast error. Independent variable is real GDP as a percentage deviation from tend. T-statistics, based on HAC Newey-West corrected standard errors, are in parentheses. A * denotes significance at the $5 \%$ level, ** denotes significance at the $1 \%$ level. Analyst forecast data is from the survey of professional forecasters, available at www.phil.frb.org/econ/liv/index.html. Data is quarterly from 1968:4 to 2003:1 (137 observations). The number of analysts varies between 9 and 76 with an average of 36 per quarter. 
Figure 1 plots the one-period ahead median forecast error and GDP percentage deviation from trend, showing a strong negative correlation. The median forecast error corresponds to the forecast error of the representative agent in the model. This measure supports our main hypothesis: forecast accuracy and output are negatively correlated. ${ }^{3}$

\section{Model}

\section{Preferences and Endowments}

An infinite-lived representative consumer ranks consumption streams $c=\left\{c_{t}\right\}_{t=0}^{\infty}$ and labor streams $n=\left\{n_{t}\right\}_{t=0}^{\infty}$ according to

$$
U=E_{0} \sum_{t=0}^{\infty} \beta^{t} u\left(c_{t}, 1-n_{t}\right),
$$

where $u$ is in $\mathcal{C}^{2,2}$, nonseparable, strictly increasing and concave in both arguments, and satisfies the Inada conditions:

$$
u\left(c_{t}, 1-n_{t}^{s}\right)=\frac{\left(c_{t}^{\sigma}\left(1-n_{t}\right)^{1-\sigma}\right)^{1-\phi}}{1-\phi}
$$

The parameters $\phi$ and $\sigma$ control risk aversion and the intratemporal elasticity of substitution between consumption and labor. The household is endowed with an initial capital stock and one unit of time each period.

\section{Firms and Technology}

Competitive firms have access to a risky Cobb-Douglas production technology $f$ that uses capital and labor as inputs. There are two types of production risk. There is an aggregate technology shock, $z_{t}$, which is a multiplier on production, and a shock $\eta_{t}$ which is additive. The shocks $\eta_{t}$ are

\footnotetext{
${ }^{3}$ Although more loosely connected to the model, we also find a negative relationship between the dispersion of analysts' forecasts of real GDP and real GDP deviations from trend (not reported). Dispersion shoots up near business cycle troughs. Median forecast errors and cross-sectional dispersion are related. Using inflation data from the Survey of Professional Forecasters, Rich and Tracy (2003) documents a stable relationship between observed heteroscedasticity in forecast errors and cross-sectional dispersion in forecasts. Veronesi (1999) shows that a similar relationship holds in financial markets. Stock returns are lower when analysts' GDP forecasts are more diffuse. This is consistent with our finding because equity returns are a leading indicator of real GDP.
} 
i.i.d. normal variables with mean zero and constant variance $\sigma_{\eta}$ :

$$
y_{t}=z_{t} f\left(k_{t}, n_{t}^{d}\right)+\eta_{t}
$$

The technology shock is specified as a two-state Markov switching process $z_{t} \epsilon\left\{z^{H}, z^{L}\right\}$. We assume that the transition matrix $\boldsymbol{\Pi}$ is symmetric to ensure that all asymmetry in the resulting dynamics is endogenous.

This specification implies that expected returns to scale are constant. In this economy, entry of new production units is unprofitable ex-ante.

Two features of the production shock are crucial for learning asymmetry. First, the production shock $\eta$ must become relatively smaller in magnitude than $z_{t} f_{t}$ at the peak of a business cycle, and relatively larger in the trough. In other words, the variance of the output shock $\sigma_{\eta}$ can rise when production increases, but must rise at a rate less than $f_{t}$. This condition implies that the signal-to-noise ratio is procyclical. For the computation, we will assume that the shock variance $\sigma_{\eta}^{2}$ is constant, although this is a more restrictive assumption than necessary for the model to function.

Appendix A.1 shows that, for a setup in which individual production units are subject to an individual shock $\eta_{t}^{i}$, the aggregate signal-to-noise ratio is procyclical. Aggregating over production units generates an output equation consistent with (2).

Second, even though the model and data are analyzed in a stationary environment, learning asymmetry should not disappear when growth is added. As the economy grows, learning will become trivial unless the standard deviation of the production shock grows at the same long-run rate as output. We will discuss one interpretation of a shock with these properties in section 5 .

\section{Information}

Let $x^{t}$ denote the $t$-history of any series $x$. The model is defined on a probability space with filtration $\mathcal{F}_{t} \equiv\left\{y^{t-1}, c^{t-1}, d^{t-1}, k^{t}, i^{t}, n^{d, t}, n^{s, t}, \theta^{t}, w^{t}, p^{t}\right\}$. All choice variables in period $t$ are $\mathcal{F}_{t^{-}}$ measurable. Neither the household nor the firm observe the current or past values of technology $z^{t}$ nor the noise $\eta^{t}$. Output $y_{t}$, dividends $d_{t}$ and consumption $c_{t}$ are not observed until the end of 
period $t$. All other variables are known at the beginning of period $t$.

Agents use a Bayesian filter to forecast $z_{t}$ given $\mathcal{F}_{t}$. This filter is composed of a Bayesian updating formula (3) and an adjustment for the possibility of a state change (4).

$$
\begin{gathered}
P\left(z_{t-1}=z^{H} \mid \mathcal{F}_{t}\right)=\frac{\phi\left(y_{t-1} \mid z^{H}, \mathcal{F}_{t-1}\right) \tilde{z}_{t-1}}{\phi\left(y_{t-1} \mid z^{H}, \mathcal{F}_{t-1}\right) \tilde{z}_{t-1}+\phi\left(y_{t-1} \mid z^{L}, \mathcal{F}_{t-1}\right)\left(1-\tilde{z}_{t-1}\right)}, \\
{\left[P\left(z_{t}=z^{H} \mid \mathcal{F}_{t}\right), P\left(z_{t}=z^{L} \mid \mathcal{F}_{t}\right)\right]=\left[P\left(z_{t-1}=z^{H} \mid \mathcal{F}_{t}\right), P\left(z_{t-1}=z^{L} \mid \mathcal{F}_{t}\right)\right] \mathbf{\Pi},} \\
\tilde{z}_{t}=\left[P\left(z_{t}=z^{H} \mid \mathcal{F}_{t}\right), P\left(z_{t}=z^{L} \mid \mathcal{F}_{t}\right)\right]\left[\begin{array}{c}
z^{H} \\
z^{L}
\end{array}\right]
\end{gathered}
$$

where $\phi$ is a normal probability density. Equation (3) applies Bayes' law to compute the posterior probability, at the beginning of time $t$, that the economy was in the high state in the preceding period. Equation (4) converts this posterior belief about the time $t-1$ state into a prior belief about the time $t$ state. The result of this updating is $\tilde{z}_{t}$, the expected technology value in period $t$. It is a convex combination of the high and low true technology states. Equations (3) and (5) form the observation and state equations of a signal extraction problem with time-varying parameters.

\section{Household Problem}

Households enter each period with a belief about technology $\tilde{z}_{t}$ and an ownership share stock portfolio $\theta_{t}$. Given wages and share prices $\left\{w_{t}, p_{t}\right\}$, they choose how much labor to supply, $n_{t}^{s}$ and what fraction $\theta_{t+1}$ of the shares of the firms to purchase. Then the additive shock $\eta_{t}$ is realized (but unobserved) and the dividend $d_{t}$ is received. Finally, the forecast of $z$ is updated.

The household problem is to maximize $U$ in equation (1) subject to a sequence of end-of-period budget constraints and interiority constraints:

$$
\begin{aligned}
& \left.c_{t}+p_{t} \theta_{t+1} \leq w_{t} n_{t}^{s}+p_{t}\right) \theta_{t}+d_{t} \theta_{t+1}, \forall t \\
& c_{t} \geq 0, \quad 0 \leq n_{t}^{s} \leq 1, \quad \theta_{0} \text { given. }
\end{aligned}
$$


Households decide on stock purchases and labor supply before the shock is realized. As a result of this timing assumption, consumption is a residual. It absorbs unexpected shocks to output coming from $z$ or $\eta$. Stock purchases finance investment projects.

\section{Firm Problem}

Competitive firms maximize lifetime expected shareholders' value.

$$
S=E_{0} \sum_{t=0}^{\infty} \beta^{t}\left(\frac{u_{c}\left(c_{t}, 1-n_{t}\right)}{u_{c}\left(c_{0}, 1-n_{0}\right)}\right) d_{t} .
$$

Firms choose how much labor to hire and how much to invest at the beginning of the period. Wages and rental rates are set at the beginning of the period. Then the shock $\eta$ is realized (but not revealed) and output $y_{t}$ is realized. The profits of the firm (negative or positive) are paid out as dividends $d_{t}$ to the households.

The firm's problem is to maximize $\mathrm{S}$ in equation (7) subject to the dividend determination equation:

$$
d_{t}=z_{t} f\left(k_{t}, n_{t}^{d}\right)+\eta_{t}-w_{t} n_{t}^{d}-i_{t}, \forall t
$$

and the capital accumulation equation:

$$
\begin{array}{r}
k_{t+1}=(1-\delta) k_{t}+i_{t}, \forall t \\
k_{t} \geq 0, \quad k_{0} \text { given. }
\end{array}
$$

Dividends, positive or negative, ensure zero profits ex-post. Because $\eta$ is normally distributed, profits have unbounded support. Households, who own the firms, face unlimited liability.

New investment projects and staffing take time to plan. Hence, the timing assumption of choosing investment and labor supply at the beginning of the period seems consistent with the fact that the National Association of Purchasing Managers index is a leading indicator of economic activity. 


\section{Equilibrium}

For a given $k_{0}$, and an initial distribution of $z_{0}$, an equilibrium is sequence of quantities $\left\{c_{t}, i_{t}, k_{t}, n_{t}^{d}, n_{t}^{s}, y_{t}, \theta_{t}\right\}_{t=0}^{\infty}$ and prices $\left\{w_{t}, p_{t}\right\}_{t=0}^{\infty}$ such that

- Given prices, households solve the household problem,

- Given prices, firms solve the firm problem,

- The markets for goods, labor, and firms' shares clear.

$$
y_{t}=i_{t}+c_{t}, \quad n_{t}^{s}=n_{t}^{d}, \quad \theta_{t}=1
$$

\section{Optimality Conditions}

Firms hire workers until the expected marginal products of labor equals the wage:

$$
w_{t}=E_{t}\left[z_{t} f_{n}\left(k_{t}, n_{t}\right)\right]
$$

Workers supply labor until the marginal rate of substitution between consumption and labor equals the wage

$$
w_{t}=\frac{E_{t}\left[u_{n}\left(c_{t}, 1-n_{t}\right)\right]}{E_{t}\left[u_{c}\left(c_{t}, 1-n_{t}\right)\right]} .
$$

Equation (11) differs from the standard condition in that the technology level $z_{t}$ and hence the marginal product of labor are unobserved. Equation (12) differs from the standard condition in that the consumption level $c_{t}$ and hence the marginal utilities of consumption and leisure are unobserved at the beginning of the period. We assume that wages are determined at the beginning of the period. In equilibrium they equal the expected marginal product of labor, which equals the ratio of the expected marginal disutility of labor to the expected marginal utility of consumption.

From the firm's first order condition with respect to capital, we obtain the Euler equation:

$$
E_{t}\left[u_{c}\left(c_{t}, 1-n_{t}\right)\right]=E_{t}\left[\beta u_{c}\left(c_{t+1}, 1-n_{t+1}\right)\left(z_{t+1} f_{k}\left(k_{t+1}, n_{t+1}\right)+1-\delta\right)\right] .
$$


The Euler equation from the household's problem is:

$$
E_{t}\left[u_{c}\left(c_{t}, 1-n_{t}\right)\right]=E_{t}\left[u_{c}\left(c_{t}, 1-n_{t}\right)\left(\frac{d_{t}}{p_{t}}\right)+\beta u_{c}\left(c_{t+1}, 1-n_{t+1}\right)\left(\frac{p_{t+1}}{p_{t}}\right)\right]
$$

Equations (13) and (14) relate the cum-dividend return on stocks to the physical return on capital invested in the firm. Learning affects the right hand side of the Euler equations by changing the joint distribution of time $t+1$ consumption and labor.

\section{Social Planner Problem}

To solve the model numerically, we work with the planner problem. The planner's problem is to maximize $U$ in equation (1) subject to the capital accumulation equation (9) and the sequence of resource constraints:

$$
c_{t}+i_{t}=z_{t} f\left(k_{t}, n_{t}\right)
$$

The planner is subject to the same timing and informational constraints as the agents in the decentralized model. The competitive equilibrium and the Pareto optimum problem are equivalent because they share the same first order conditions, the goods market clearing condition is identical to the planner's resource constraint, technology is convex, and preferences insatiable.

The planner's problem can be formulated in a recursive fashion. The state variables are the expected value of technology and the capital stock: $s_{t}=\left(\tilde{z}_{t}, k_{t}\right)$. The planner enters the period with a capital stock $k_{t}$ and a forecast of the technology shock $\tilde{z}_{t}$. Then, he chooses $n_{t}$ and $i_{t}$. Next,

$z_{t}$ and $\eta_{t}$ and hence $y_{t}$ are realized, but only $y_{t}$ is observed. Finally, the forecast of $z$ is updated and consumption is determined as a residual. The value function $V\left(s_{t}\right)$ solves the following Bellman equation:

$$
\begin{gathered}
V\left(k_{t}, \tilde{z}_{t}\right)=\max _{i_{t}, n_{t}} u\left(c_{t}, 1-n_{t}\right)+\beta E\left[V\left(k_{t+1}, \tilde{z}_{t+1}\right) \mid \mathcal{F}_{t}\right] \\
\text { subject to } k_{t+1}=(1-\delta) k_{t}+i_{t} \\
c_{t}=z_{t} f\left(k_{t}, n_{t}\right)+\eta_{t}-i_{t}
\end{gathered}
$$




$$
c_{t} \geq 0,0 \leq n_{t} \leq 1, k_{t} \geq 0, \text { and } k_{0} \text { given, }
$$

taking updating rules (3) (4) and (5) as given.

In choosing optimal policies, we assume that the planner does not take into account the effect of labor and investment choices on the evolution of beliefs. This assumption rules out active experimentation, the costly provision of information. A planner economy with active experimentation has no decentralized counterpart because information externalities invalidate the welfare theorems. In a decentralized economy, information is a public good. Information provision is subject to a free-rider problem. In a large economy, the provision of this public good would fall to zero. Therefore, households and firms do not take into account the effect of their actions on the evolution of aggregate beliefs. To implement passive learning, the planner iterates on the following algorithm. First, given beliefs about $\mathcal{F}_{t+1}$, he chooses policies. Second, given policies, he updates beliefs. The iteration stops when beliefs and policies are consistent. ${ }^{4}$

\section{Interpreting the Production Shock}

One possible way to interpret the additive production shock $\eta$ is as the contribution of intangible capital to output. Intangible capital is a fixed production factor: its size does not fluctuate over the business cycle. Examples of intangible fixed factors are the non-labor and non-capital components of senior management, branding \& marketing, or research \& development. Because much of the surplus generated by these factors is firm-specific, it is unlikely to be paid in full to the managers or marketers. Instead, some of the surplus from these activities will remain with the firm, increasing its market value.

The signal extraction problem should be relatively easy for firms or industries that are relatively intensive in tangible capital. This is because the signal-to-noise ratio is much larger than one. Firms in the manufacturing sector or firms with a large book-to-market value ratio fall into this category. Firms or industries with a tangible to intangible capital ratio closer to one are predicted to show more asymmetry in output. When the signal-to-noise ratio is near one, cyclical changes in the ratio

\footnotetext{
${ }^{4}$ Quantitatively, using active or passive learning makes a small difference for policy rules in the planner problem.
} 
have the largest effect. Technology firms or firms with a small book-to-market ratio (around 0.5) fall into this category. Future work will test this cross-sectional prediction with asset price data. Hall (2001) also relates the value of firms' intangibles to stock returns.

\section{Production Shocks in a Growth Economy}

Our formulation of the additive noise term is consistent with asymmetry that does not vanish in a growing economy. In an economy with growth, the contribution of the additive shock $\eta$ to output increases at the long-run growth rate of the economy, keeping the long-run signal-to-noise ratio constant. There are constant returns to scale in the long-run.

In a stationary environment, the model assumes that the variance of $\eta$ is constant over the business cycle. Firms cut investment projects and lay off workers as soon as the economy rounds the business cycle peak, but fixed factors such as patents, senior management and brand name stay relatively constant. In an economy with growth rate $\gamma$, intangible factors' contribution to output $\gamma \eta$ must increase in magnitude at the long-run growth rate of output (and production). If this were not the case, the signal-to-noise ratio would fall over time, the signal extraction problem would become easier and asymmetry would eventually disappear. Table 3 shows the skewness in monthly and quarterly changes in industrial production by decade. The industrial production data does not support the hypothesis that asymmetry is disappearing over time.

\section{Data, Calibration and Computation}

If crashes are more sudden than booms, then the most extreme downward changes in output will be larger in magnitude than the largest upward movements. These changes are measured as differences in the log of output. If the negative changes are more extreme, then the unconditional distribution of log differences will exhibit negative skewness.

\section{Data}

We begin the calibration exercise by computing second and third moments of macroeconomic aggregates for the last 50 years. Table 4 lists moments of U.S. output (y), capital(k), employment (n), 
and consumption (c). All data are quarterly from 1952:1 until 2002:1. Output data is from U.S. Department of Commerce, Bureau of Economic Analysis (BEA). Quarterly capital data is obtained by combining an annual capital stock series from the fixed asset tables of the BEA and quarterly fixed private investment from the Bureau of Economic Analysis used to interpolate between the years. Similarly, quarterly hours worked is constructed using quarterly employment (BLS data: non-farm, seasonally adjusted) to interpolate between yearly hours worked (from the BEA). Nominal GDP, consumption and investment are deflated with their respective GDP deflators (all from BEA). All variables are per-capita, where the total population data is from the Census Bureau.

\section{Methods of Detrending}

The choice of detrending procedure is not innocuous for the asymmetry measure. Equally critical is the time horizon of changes in the data. To get a full picture of the frequencies at which growth asymmetry in output appears, we examine various choices of filters and horizons.

The most common filters are the Hodrick and Prescott (1997) filter and the Baxter and King (1995) bandpass filter. Both are two-sided, meaning that they use information both from the past and the future to estimate the filtered value. The use of a two-sided filter raises two issues. First, in a non-stationary version of the model, agents would not have access to the future information necessary to detrend. Second, if the trend line starts to fall because a sudden crash is ahead, this will reduce the magnitude of the crash in the detrended data. A one-sided version of the bandpass filter does not have these drawbacks. Finally, we use geometric detrending with two break points to account for the productivity slowdown in the 1970's. We compare these detrending methods to a simple log difference of the raw data in table 2 .

\begin{tabular}{||c|ccccc||}
\hline & HP & Band Pass & One-Sided & Log Dif. & Geometric \\
\hline GDP & 0.06 & -0.44 & -0.22 & -0.40 & -0.29 \\
\hline
\end{tabular}

Table 2: Skewness in detrended Output. Results are for 5 different detrending procedures: Hodrick-Prescott, Baxter-King, 1-sided bandpass constructed with the MATLAB command invfreqz, log differences and geometric detrending with breakpoints in 1969:4 and 1980:3. Data are for real per capita GDP between 1952:1 and 2002:4.

Multi-period Changes To capture the idea that slow booms and big crashes do not necessarily occur at one quarter horizons, we examine skewness of $N$-period changes in output, varying $\mathrm{N}$ 
between 1 and 16 quarters. Figure 2 plots these N-period skewness for the four detrending methods, during the overlapping sample period, 1956:1 to 1998:1. In spite of the level differences, all methods show negative skewness in output. Negative skewness diminishes, and eventually vanishes at horizons of around 3-4 years. Thus, negative skewness is a subtle but robust feature of the data that mainly arises as a 1 to 12 quarter phenomenon.

\section{Calibration}

Following Kydland and Prescott (1982), and Cooley and Prescott (1995), we calibrate the model at quarterly frequency. The depreciation rate of $\delta=0.012$ matches the investment to capital ratio and the discount factor $\beta=0.98$ is chosen to match the capital to output ratio. Since the data is quarterly, $\delta$ and $(1-\beta)$ are one-fourth of their annual rates. Preference parameter $\sigma=0.386$ is chosen such that steady state labor supply is $1 / 3^{r d}$. Production is Cobb-Douglas with exponent $\alpha=0.34$ chosen to match the labor share of income. Both labor hours and the fraction of labor income are fairly constant in the post-war U.S. data. Finally, we choose the coefficient of relative risk aversion to be $\phi=4$ and check the robustness of our results with low risk aversion $\phi=2$.

Three parameters are specific to our learning model. These are the probability of a change in the technology state, the relative values of those states, and the variance of the production shock $\sigma_{\eta}^{2}$ . The probability of a technology change is chosen so that the implied autocorrelation of technology matches Cooley and Prescott (1995)'s estimate of 0.95. The absolute level of the technology state is unimportant since results compare percentage deviations from trend. However, the distance between $z^{H}$ and $z^{L}$ will determine the volatility of technology. On the basis of estimates of Solow residuals, Cooley and Prescott (1995) set the standard deviation of the technology shock at 0.007 in an $\mathrm{AR}(1)$ specification for $\ln (z)$. In our formulation, this corresponds to a technology process with standard deviation of 0.032 . Setting $z^{H}$ and $z^{L}$ to $(1+0.032,1-0.032)$ produces the same standard deviation.

The shock variance $\sigma_{\eta}^{2}$ is important because it determines how easy or difficult it is to learn $z$. If the shocks are large, estimates will be bad and agents will have difficulty learning that transitions have occurred. If the shocks are very small, learning becomes trivial. The standard deviation of 
the shock $\sigma_{\eta}=0.02$ is chosen to match the observed correlation between the median forecast error and observed real GDP.

\section{Computational Details}

To estimate the value function and policy rules for the social planner, we use value iteration on a grid, with linear interpolation between nodes. There are two continuous state variables: the capital stock, $k_{t}$, and the believed technology level, $\tilde{z}_{t}$. Because capital leaves the grid in some states of the world, we need an extrapolation method. We use the function $V_{z}(k)=-\psi k^{-\kappa}$ and determine the two unknown coefficients by matching the level and slope of the interpolated function at the grid boundaries. The value of infinite capital is zero, and zero capital has negative infinite value.

We simulate the model for 50,000 periods and compute statistics on 250 sub-samples of 200 periods each. This is the length of the data. Skewness of the first-differenced simulated data is our measure of growth asymmetry.

\section{Learning and Output Volatility}

A significant challenge in comparing the model to data lies in a fundamental tension between learning and output volatility. If the (i.i.d.) shock $\eta$ is to disguise the true technology state $z$, then it has to be big enough to make a boom look like a recession. Any process that would make learning non-trivial would also imply an unrealistically high volatility and low autocorrelation in output.

To resolve this conflict, the time series that we compare to observed GDP data is not $y$, but rather the estimate of the persistent component of output at the end of the period, $\hat{y}$. The reason a data collecting agency might want to report $\hat{y}$ is because a measure of the persistent component of output is useful for predicting future outcomes. To be precise, the data collecting agency would like to report $y_{t}-\eta_{t}$, but does not observe $\eta$. Instead, it constructs and reports a filtered GDP series, given public information available at the end of the period: $\hat{y}_{t}=E\left[z_{t} \mid \mathcal{F}_{t+1}\right] f\left(k_{t}, n_{t}\right)$. The filtered time series $\hat{y}$ can be interpreted as revised data. ${ }^{5}$ The interpretation of $\eta$ as the contribution of

\footnotetext{
${ }^{5}$ An alternative view of GDP revisions is that they correct measurement error. However, Mankiw and Shapiro (1986) and Grimm and Parker (1998) find empirical evidence that subsequent revisions to US GNP/GDP growth
} 
intangibles to output is consistent with this goal of revisions since intangibles are likely to be a component of output that is poorly-measured and hard to predict. Lastly, for the national income accounts to balance, consumption must be filtered in a manner identical to output. Consumption is a residual determined by $\hat{c}_{t}=\hat{y}_{t}-i_{t}$.

Three pieces of empirical evidence support the interpretation of observed GDP as filtered estimates. First, revisions to GDP are often quite large. Mean absolute revision from preliminary to final estimates of annual US real GDP growth data are 1.3 percentage points for the period 1983-2000. Data collecting agencies report revisions to previous estimates that make use of data available only after the period to which the estimate pertains, i.e. they filter (see Fixler and Grimm (2002)). Second, Faust, Rogers and Wright (2001) study GDP announcements for different countries and show that successive revisions move GDP estimates closer to trend. They conclude that revisions reflect the removal of idiosyncratic "noise" from the series. Third, the Bank of England, one of the only banks that disclose their estimation procedure, explicitly states that a goal of GDP revisions is to reduce "variation around a relatively fixed level" (ESA95 Inventory, Chapter 2.1, p.33, January 2001).

\section{Results}

\section{No-Learning Model}

To isolate the effect of learning on business cycles, we compute results for a calibrated version of the model with no learning. The model is identical to the learning model except that the technology level is revealed at the start of each period: $z^{t} \in \mathcal{F}^{t}$. This no-learning model differs from the standard real business cycle model in the literature in two respects. First, technology follows a Markov switching, rather than an AR(1) process. Second, and more substantively, there are additive $i . i . d$. shocks to output. Since labor and investment are chosen at the beginning of the period, the shocks move consumption around. Agents insure against a bad shock to consumption

data display increasing variances. Increasing variances is consistent with updating filtered estimates, but inconsistent with successive reduction of measurement error. Sargent (1989) combines both views in an economy where a data collecting agency observes error-ridden data, but reports a filtered version. The filtering also generates a reported time series that is smoother than the true output. 
by investing less and working more.

Moments of the simulated no-learning model are summarized in table 6. Following Cooley and Prescott (1995), we HP-filter all simulation results before comparing second moments in model and in the data. Because of the distortionary effect of the two-sided HP filter on skewness, we compute skewness of changes in the unfiltered series.

In matching the second moments, this model suffers from the same problems as the original real business cycle models. One example is the low volatility of labor. Changing from CES preferences to Hansen (1985) preferences could remedy this.

Even without learning, the model generates some asymmetry. This asymmetry comes from the assumption that consumption is a residual that absorbs output shocks. When productivity has been high and falls, agents slash investment in order to prevent a large fall in consumption. When

productivity has been low and rises, a small capital stock keeps the output level low. An aggressive investment policy with small planned consumption could result in an unexpected consumption disaster. Instead, risk-averse agents increase investment slowly as output rises, and the "boom" is more gradual. This asymmetry can be seen in the negative skewness of output estimates, labor, and investment. This is one source of asymmetry in the model. However, it can reproduce only half the asymmetry in the output and it does not produce any skewness statistics that are significantly different from zero.

\section{Learning Model}

To match the third moments of the data, the learning mechanism is needed. The learning model (table 7) matches the asymmetry in output, labor and capital. All of the aggregates, except capital, have skewnesses that are significantly different from zero. For investment, the model skewness is too low, but the point estimate in the data is within the 95 percent confidence interval of the model's skewness.

Due to the smoothing effect of estimating trend GDP, the volatility of output is slightly too low. This tells us that, if governments are releasing smoothed estimates as GDP numbers, the volatility of productivity shocks may be higher than previously estimated. Lowering the risk aversion parameter 
remedies the problem somewhat, while leaving the third moments largely unchanged (table 8).

The model can also reproduce the pattern of negative but diminishing skewness, as the horizon increases. The reason skewness diminishes is that 80 percent of the change in output from the boom or crash occurs within 8 periods, on average. Changes over a period that includes the entire boom or crash will not measure the speed of these movements. Skewness in multi-period output changes is reported in figure 3, which plots the skewness of $\left(y_{t}-y_{t-N}\right)$ for the learning model, using different detrending methods. The model starts off with short-horizon asymmetry below zero. The asymmetry approaches zero as the horizon lengthens. Finally, we compare the N-period skewnesses for the learning and the no-learning model (figure 4). Asymmetry in the no-learning model disappears after 9 quarters. In the learning model, asymmetry diminishes, but stays negative at all horizons, similar to the log-difference and geometrically detrended data in figure 2 .

Another way to see the effect learning has on asymmetry is to vary the difficulty of learning. The theory predicts that both high-noise (high $\sigma_{\eta}$ ) and low-noise (low $\sigma_{\eta}$ ) environments should have little asymmetry. Asymmetry should be strongest where learning is neither impossible nor trivial. Figure 5 shows that output skewness is most negative when the variance of $\eta$ is close to half the variance in output. As the ratio of noise to output variance approaches zero and one, skewness approaches zero.

Finally, we ask what is the effect of our assumption that agents are all passive, rather than active learners? We solve a model in which there is no separation between the filtering and the control problem. Table 9 summarizes the results. The second and third moments are close to the ones we obtain for the passive learning environment.

\section{Welfare Analysis}

Accounting for asymmetries can have important implications for predicting the future fluctuations of macroeconomic aggregates. To isolate the cost of ignoring learning asymmetry, we consider two agents. The first agent updates beliefs, using the model specified in this paper. The second agent

is unaware of the learning asymmetry in the economy. He believes that the standard deviation of the additive shock is proportional to production $f_{t}$, making learning equally difficult throughout 
the business cycle. Placing both of these agents in the environment of our model, we ask how the one with the misspecified model fares, relative to the agent who understands learning asymmetry.

To compare the welfare of our two agents, we compute the total cost of business cycles for each agent. Lucas (1987) defines the total cost of business cycles as the compensation in consumption, $\chi$, needed to equalize lifetime utility with a world without business cycles.

$$
E_{0} \sum_{t=1}^{\infty} \beta^{t} u\left((1+\chi) c_{t}, n_{t}\right)=\sum_{t=1}^{\infty} \beta^{t} u\left(E_{0}\left(c_{t}, n_{t}\right)\right)
$$

The sources of risk in the model are technology shocks $z$ and the additive shocks $\eta$.

We find that the cost of business cycles for the agent with the misspecified model is $3.8 \%$ higher. The consumption multipliers, $\chi$, are $0.16 \%$ and $0.15 \%$ for the agents with the asymmetric and symmetric models. Given the low volatility of consumption and hours worked in the standard RBC model, the small costs are not surprising. However, to the extent we think there are gains from reducing business cycle fluctuations, this result suggests some benefits from understanding the source of asymmetry.

\section{Conclusion}

Learning about the technology level over a business cycle can generate asymmetry in booms and crashes. The reason for the asymmetry is that when agents believe that the level of technology is high, they invest more and work harder. Because technology movements are amplified by the production function, more production makes the technology process is more transparent. It becomes easier to forecast the future accurately. Because of the mean-reversion in technology, large downturns are most likely when technology is high and large upturns when technology is low. Therefore, when large downturns happen, agents quickly develop accurate estimates of the decline. The high speed of learning at the peak of a cycle causes the response to a bad technology shock to be sudden and the high precision of the estimates causes that reaction to be large. Booms happen when production is low and it is very difficult to observe changes in technology. more gradual changes in beliefs and more uncertainty about increases in technology cause booms to be more gradual. We 
embed this mechanism into a dynamic stochastic general equilibrium model.

While suffering from the same second moment problems as a standard model, the learning model is a substantial improvement in matching the asymmetry in output, investment and employment. As in the data, the model predicts that the degree of asymmetry diminishes at lower frequencies.

The crucial assumption for asymmetric learning is the assumption that the standard deviation of the idiosyncratic shocks does not rise proportionately with production over the business cycle. If noise and signal grew at the same rate, then the filtering problem would be just as difficult in good times and bad. Data on analyst forecasts support the main premise of the model, that uncertainty varies counter-cyclically. This work suggests that there are significant asymmetries in the data that can be explained by uncertainty and learning about productivity over the business cycle.

The results may shed some light on related asset-pricing puzzles. Asymmetric learning generates counter-cyclical uncertainty that may account for counter-cyclical movements in asset price volatility (Bekaert and Wu (2000)), counter-cyclical equity premia (Campbell and Cochrane (1999)) and return asymmetry (Chen, Hong and Stein (2001)). To generate quantitatively meaningful asymmetry predictions for asset pricing, this model would need to be augmented with habit persistence (Boldrin, Christiano and Fisher (2001)) or frictions such as endogenous borrowing constraints (Lustig and VanNieuwerburgh (2002)). 


\section{References}

Acemoglu, Daron and Andrew Scott, "Asymmetric Business: Theory and Time-Series Evidence," Journal of Monetary, 1997, 40, 501-33.

Backus, David, Patrick Kehoe, and Finn Kydland, "International Real Business Cycles," Journal of Political Economy, 1992, 100 (4), 745-75.

Baxter, Marianne and Robert King, "Measuring Business Cycles: Approximate Band-Pass Filters for Economic Time Series," 1995. NBER Working Paper no 5022.

Bekaert, Geert and Guojun Wu, "Asymmetric Volatility and Risk in Equity Markets," The Review of Financial Studies, 2000, 13 (1), 1-42.

Boldrin, Michele and David Levine, "Growth Cycles and Market Crashes," Journal of Economic Theory, 2001, 96, 13-39.

, Lawrence Christiano, and Jonathan Fisher, "Habit Persistence, Asset Returns, and the Business Cycle," American Economic Review, March 2001, 91 (1), 149-66.

Cagetti, Marco, Lars Hansen, Thomas Sargent, and Noah Williams, "Robustness and Pricing with Uncertain Growth," Review of Financial Studies, 2001, 15 (2).

Campbell, John and John Cochrane, "By Force of Habit: A Consumption-Based Explanation of Aggregate Stock Market Behavior.," Journal of Political Economy, 1999, 107 (2), 205-251.

Chakley, Martin and In-Ho Lee, "Learning and Asymmetric Business Cycles," Review of Economic Dynamics, 1998, 1, 623-45.

Chamley, Christophe and Douglas Gale, "Information Revelation and Strategic Delay in a Model of Investment," Econometrica, 1994, 62 (5), 1065-85.

Chen, Joseph, Harisson Hong, and Jeremy Stein, "Forecasting Crashes : Trading Volume, Past Returns, and Conditional Skewness in Stock Prices," Journal of Financial Economics, September 2001, 61 (3), 345-81.

Cogley, Timothy, "How Fast Can the New Economy Grow? A Bayesian Analysis of the Evolution of Trend Growth," August 2002. Mimeo Arizona State University.

Cooley, Thomas and Edward Prescott, Frontiers of Business Cycle Research, Princeton, NJ: Princeton University Press, 1995.

Ebell, Monique, "Why Are Asset Returns More Volatile During Recessions? A Theoretical Explanation," 2001. Working Paper Studienzentrum Gerzensee Workin Paper No. 01.01.

Evans, George, Seppo Honkapohja, and Paul Romer, "Growth Cycles," American Economic Review, 3 1998, 88 (June), 495-515.

Faust, Jon, John Rogers, and Jonathan Wright, "News and Noise in G-7 GDP Announcements," October 2001. Mimeo Federal Reserve Board, International Finance Division.

Fixler, Dennis and Bruce Grimm, "Reliability of GDP and Related NIPA Estimates," Survey of Current Business, January 2002, pp. 9-27. 
Grimm, Bruce and Robert Parker, "Reliability of the Quarterly and Annual Estimates of GDP and Gross Domestic Income," Survey of Current Business, December 1998, pp. 12-21.

Hall, Robert E., "The Stock Market and Capital Accumulation," American Economic Review, 2001, 91, 1185-1202.

Hansen, Garey, "Indivisible Labor and the Business Cycle," Journal of Monetary Economics, 1985, 16, 309-27.

and Edward Prescott, "Capacity Constraints, Asymmetries and the Business Cycle," October 2000. mimeo.

Hodrick, Robert and Edward Prescott, "Post-War U.S. Business Cycles: An Empirical Investigation," Journal of Money, Credit and Banking, 1997, 29, 1-16.

Jovanic, Boyan and Yaw Nyarko, "Learning by Doing and the Choice of Technology," Econometrica, 1982, 50 (6), 1345-70.

Jovanovic, Boyan, "Asymmetric Cycles," April 2003. NYU Working Paper.

Kasa, Kenneth, "Signal Extraction and the Propagation of Business Cycles," 1995. Federal Reserve Bank of San Francisco Working Papers in Applied Economic Theory, no.95-14.

Kocherlakota, Narayana, "Creating Business Cycle Through Credit Constraints," Federal Reserve Bank of Minneapolis Quarterly Review, 2000, 24 (3), 2-10.

Kydland, Finn and Edward Prescott, "Time to Build and Aggregate Fluctuations," Econometrica, November 1982, 50 (6), 1345-70.

Lang, William and Leonard Nakamura, "The dynamics of credit markets in a model with learning," Journal of Monetary Economics, 1990, 26, 305-18.

Lucas, Robert, Models of Business Cycles Yrjo Jahnsson Lecture Series, London: Blackwell, 1987.

Lustig, Hanno and Stijn VanNieuwerburgh, "Housing Collateral, Consumption Insurance and Risk Premia," December 2002. Mimeo.

Mankiw, Gregory and Matthew Shapiro, "News or Noise? An Analysis of GNP Revisions," Survey of Current Business, May 1986, 66, 20-25.

Neftci, Salih, "Are Economic Times Series Asymmetric Over the Business Cycle?," Journal of Political Economy, April 1984, 92 (2), 307-28.

Potter, Simon, "Fluctuations in Confidence and Asymmetric Business Cycles," 1999. Mimeo Federal Reserve Bank of New York.

Rich, Robert and Joseph Tracy, "Modeling Uncertainty: Predictive Accuracy as a Proxy for Predictive Confidence," February 2003. Federal Reserve Bank of New York Staff Reports no 161.

Rob, Rafael, "Learning and Capacity Expansion under Demand Uncertainty," Review of Economic Studies, 1991, 58 (4), 655-75. 
Sargent, Thomas, "Two Models of Measurement and the Investment Accelerator," Journal of Political Economy, 1989, 97 (2), 251-87.

Veldkamp, Laura, "Slow Boom, Sudden Crash," August 2001. SIEPR Discussion Paper no.00-16.

Veronesi, Pietro, "Stock Market Overreaction to Bad News in Good Times: A Rational Expectations Equilibium Model," The Review of Financial Studies, 1999, 12 (5), 975-1007.

Williams, Noah, "Small Noise Asymptotics for a Stochastic Growth Model," 2002. Mimeo, Princeton University.

Zeira, Joseph, "Informational Overshooting, Booms and Crashes," Journal of Monetary Economics, 1999, 43, 237-57.

\section{A Appendix}

\section{A.1 Aggregation over Productive Units}

This appendix shows that the main feature of the model, that the signal-to-noise ratio is procyclical, is preserved under aggregation. Model predictions are agnostic about the scale of operation and the number of production units (industries, firms or plants). We show the following two properties. First, holding the number of production units fixed, if the scale of production units varies over the business cycle, then the aggregate signal-to-noise ratio is procyclical. Second, holding the scale of a productive unit fixed, if the number of production units varies over the business cycle, then the aggregate signal-to-noise ratio is also procyclical.

The output of each production unit is given by $y_{t}^{i}=z_{t} f\left(k_{t}^{i}, n_{t}^{i}\right)+\eta_{t}^{i}$. Let there be $N$ productive units in the economy each operating at a scale $f_{t}^{i}=f\left(k_{t}^{i}, n_{t}^{i}\right)$. The technology shock is aggregate and continues to follow a 2 -state Markov chain with variance $\sigma_{z}^{2}$. The function $f$ is increasing, concave, and twice continuously differentiable in both arguments and is homogenous of degree one. The additive productivity shock $\eta_{t}^{i}$ is normally distributed with mean zero and constant variance $\sigma_{\eta}^{2}$.

We investigate two (natural) cases for the cross-correlation of additive shocks:

- (i) $\operatorname{Corr}\left(\eta_{t}^{i}, \eta_{t}^{j}\right)=0, \forall(i, j)$ and

- (ii) $\operatorname{Corr}\left(\eta_{t}^{i}, \eta_{t}^{j}\right)=1, \forall(i, j)$.

The aggregate output equation $y_{t}=z_{t} f\left(k_{t}, n_{t}\right)+\eta_{t}$ is obtained by summing over the outputs of individual production units. By definition $\eta_{t}=\sum_{i=1}^{N} \eta_{t}^{i}$ and $f\left(k_{t}, n_{t}\right)=\sum_{i=1}^{N} f\left(k_{t}^{i}, n_{t}^{i}\right)$.

First, because the variance of the additive shock $\eta_{t}^{i}$ is constant over the business cycle and production $f_{t}^{i}$ is procyclical, the individual production unit's signal-to-noise ratio is procyclical and equals $\left(f_{t}^{i}\right) \frac{\sigma_{z}}{\sigma_{\eta}}$.

Proposition 1. For any $\operatorname{Corr}\left(\eta_{t}^{i}, \eta_{t}^{j}\right), \forall(i, j)$, if the individual signal-to-noise ratio is procyclical but the number of firms is constant over the business cycle, then the signal-to-noise ratio is procyclical at the aggregate level.

With $N$ production units, the aggregate signal-to-noise ratio is: (i) $\sqrt{(} N)\left(f_{t}^{i}\right) \frac{\sigma_{z}}{\sigma_{\eta}}(i i)\left(f_{t}^{i}\right) \frac{\sigma_{z}}{\sigma_{\eta}}$. In each case (and any intermediate case) and for any given level of $N$, the aggregate signal-to-noise ratio is at least as procyclical at the aggregate as at the production unit level.

Second, let each productive unit produce 1 unit of consumption good: $f_{t}^{i}=1$. Then, by construction, the signal-to-noise ratio is constant over the business cycle at the level of the production unit and equal to $\frac{\sigma_{z}^{2}}{\sigma_{\eta}^{2}}$.

Proposition 2. If $\operatorname{Corr}\left(\eta_{t}^{i}, \eta_{t}^{j}\right)<1, \forall(i, j)$, the number of firms is procyclical, and the individual signal-to-noise ratio is constant over the business cycle, then the signal-to-noise ratio is procyclical at the aggregate level.

With $N$ production units in the economy, the aggregate signal-to-noise ratio is $\sqrt{(} N) \frac{\sigma_{z}}{\sigma_{\eta}}$ in case (i) and $\frac{\sigma_{z}}{\sigma_{\eta}}$ in case (ii). In case (ii), the aggregate signal-to-noise ratio is independent of the business cycle. Because the number of production units $N$ is procyclical, the aggregate signal-to-noise ratio is procyclical as long as the cross-correlation of additive shocks is strictly less than one (for all intermediary cases).

The difference between the above setups is that in the first one, there are $N$ signals observed but the quality of the individual signals varies procyclicly. In the second formulation, there is a constant signal quality at the individual level, but there is a procyclical number of signals. Either mechanism supports an aggregate production function with a procyclical signal-to-noise ratio. 


\section{A.2 Tables and Figures}

\begin{tabular}{||l|c|c|c|c|c|c|c||}
\hline & $40 \mathrm{~s}$ & $50 \mathrm{~s}$ & $60 \mathrm{~s}$ & $70 \mathrm{~s}$ & $80 \mathrm{~s}$ & $90 \mathrm{~s}$ & $1940-2001$ \\
\hline Monthly & -0.98 & 0.56 & -0.02 & -1.01 & -0.22 & -0.23 & -0.74 \\
Data & $(0.87)$ & $(0.08)$ & $(0.56)$ & $(0.97)$ & $(0.78)$ & $(0.83)$ & $(0.76)$ \\
\hline Quarterly & -2.48 & 0.10 & 0.88 & -2.05 & -0.70 & -0.87 & -2.02 \\
Data & $(0.88)$ & $(0.26)$ & $(0.96)$ & $(0.96)$ & $(0.96)$ & $(1.00)$ & $(0.79)$ \\
\hline
\end{tabular}

Table 3: Skewness of industrial production by decade. In parentheses is the probability of skewness less than zero, estimated by bootstrap.

\begin{tabular}{||l|c|c|c|c|c||}
\hline & $\begin{array}{c}\text { standard } \\
\text { deviation }\end{array}$ & $\begin{array}{c}\text { relative std } \\
\text { deviation }\end{array}$ & $\begin{array}{c}\text { first-order } \\
\text { autocorrelation }\end{array}$ & $\begin{array}{c}\text { correlation } \\
\text { with y }\end{array}$ & skewness \\
\hline $\mathrm{y}$ & 1.69 & 1.00 & 0.85 & 1.00 & -0.40 \\
\hline inv & 7.41 & 4.39 & 0.79 & 0.89 & -0.72 \\
\hline $\mathrm{n}$ & 1.55 & 0.92 & 0.89 & 0.85 & -0.16 \\
\hline $\mathrm{k}$ & 0.27 & 0.16 & 0.96 & 0.31 & -0.11 \\
\hline $\mathrm{c}$ & 1.26 & 0.74 & 0.84 & 0.89 & -0.33 \\
\hline
\end{tabular}

Table 4: Descriptive Statistics. Macroeconomic aggregates from 1952:3-2002:2 (200 observations). All series are real, per-capita. Second moments computed for percentage deviations from Hodrick-Prescott trend. Skewness is of the firstdifferenced log series.

\begin{tabular}{||l|c|c||}
\hline parameter & standard RBC & Learning \\
\hline$\delta$ & 0.0186 & 0.0186 \\
\hline$\alpha$ & 0.985 & 0.98 \\
\hline$\sigma$ & 0.34 & 0.34 \\
\hline$\phi$ & 0.375 & 0.386 \\
\hline $\operatorname{Corr}\left(z_{t}, z_{t-1}\right)$ & $A R(1)=0.95$ & $P\left(z_{t+1}=z_{t}\right)=.975$ \\
\hline $\operatorname{std}(\mathrm{z})$ & 0.032 & $\left\{z^{H}, z^{L}\right\}=\{0.968,1.032\}$ \\
\hline$\sigma_{\eta}$ & na & 0.02 \\
\hline
\end{tabular}

Table 5: Benchmark Parameters. Model parameters and their counterparts in a standard business cycles model. The output shock variance $\left(\sigma_{\eta}\right)$ is calibrated to GDP forecast errors. 


\begin{tabular}{||l|c|c|c|c|c||}
\hline & $\begin{array}{c}\text { standard } \\
\text { deviation }\end{array}$ & $\begin{array}{c}\text { relative std } \\
\text { deviation }\end{array}$ & $\begin{array}{c}\text { First-order } \\
\text { autocorrelation }\end{array}$ & $\begin{array}{c}\text { correlation } \\
\text { with GDP }(\hat{y})\end{array}$ & skewness \\
\hline$\hat{y}$ & 1.63 & 1.00 & 0.71 & 1.00 & -0.23 \\
& $(0.028)$ & $(0.000)$ & $(0.004)$ & $(0.000)$ & $(0.177)$ \\
\hline inv & 6.34 & 3.88 & 0.70 & 0.97 & -0.24 \\
& $(0.109)$ & $(0.012)$ & $(0.004)$ & $(0.013)$ & $(0.177)$ \\
\hline $\mathrm{n}$ & 0.57 & 0.35 & 0.70 & 0.97 & -0.16 \\
& $(0.010)$ & $(0.002)$ & $(0.004)$ & $(0.009)$ & $(0.176)$ \\
\hline $\mathrm{k}$ & 0.41 & 0.30 & 0.95 & 0.04 & -0.01 \\
& $(0.007)$ & $(0.026)$ & $(0.001)$ & $(0.009)$ & $(0.052)$ \\
\hline$\hat{c}$ & 0.80 & 0.50 & 0.72 & 0.99 & -0.18 \\
& $(0.014)$ & $(0.008)$ & $(0.004)$ & $(0.000)$ & $(0.167)$ \\
\hline
\end{tabular}

Table 6: No-Learning Model. Second moments are computed for percentage deviations from HP trend. Skewness is of first-differenced series. $\hat{y}, \hat{c}$ are the true persistent components of output and consumption. 50,000 simulations. Standard errors(in parentheses) are computed from 250 sample moments of series, each 200 observations long.

\begin{tabular}{||l|c|c|c|c|c||}
\hline & $\begin{array}{c}\text { standard } \\
\text { deviation }\end{array}$ & $\begin{array}{c}\text { relative std } \\
\text { deviation }\end{array}$ & $\begin{array}{c}\text { First-order } \\
\text { autocorrelation }\end{array}$ & $\begin{array}{c}\text { correlation } \\
\text { with GDP }(\hat{y})\end{array}$ & skewness \\
\hline$\hat{y}$ & 1.52 & 1.00 & 0.79 & 1.00 & -0.41 \\
& $(0.022)$ & $(0.000)$ & $(0.004)$ & $(0.000)$ & $(0.084)$ \\
\hline inv & 6.15 & 3.98 & 0.70 & 0.82 & -0.42 \\
& $(0.088)$ & $(0.007)$ & $(0.006)$ & $(0.004)$ & $(0.096)$ \\
\hline n & 0.55 & 0.36 & 0.70 & 0.82 & -0.33 \\
& $(0.008)$ & $(0.001)$ & $(0.006)$ & $(0.004)$ & $(0.097)$ \\
\hline k & 0.40 & 0.26 & 0.96 & -0.15 & -0.04 \\
& $(0.006)$ & $(0.001)$ & $(0.001)$ & $(0.004)$ & $(0.055)$ \\
\hline$\hat{c}$ & 1.09 & 0.72 & 0.29 & 0.82 & -0.22 \\
& $(0.014)$ & $(0.003)$ & $(0.009)$ & $(0.001)$ & $(0.079)$ \\
\hline
\end{tabular}

Table 7: Learning Model. Second moments are computed for percentage deviations from HP trend. Skewness is of first-differenced series. $\hat{y}, \hat{c}$ are agents' estimated persistent components of output and consumption. The coefficient of relative risk aversion is $\phi=4$. We conduct 50,000 simulations. Standard errors (in parentheses) are computed from 250 sample moments of series, each 200 observations long. 


\begin{tabular}{||l|c|c|c|c|c||}
\hline & $\begin{array}{c}\text { standard } \\
\text { deviation }\end{array}$ & $\begin{array}{c}\text { relative std } \\
\text { deviation }\end{array}$ & $\begin{array}{c}\text { First-order } \\
\text { autocorrelation }\end{array}$ & $\begin{array}{c}\text { correlation } \\
\text { with GDP }(\hat{y})\end{array}$ & skewness \\
\hline$\hat{y}$ & 1.57 & 1.00 & 0.79 & 1.00 & -0.37 \\
$(0.023)$ & $(0.00)$ & $(0.004)$ & $(0.000)$ & $(0.082)$ \\
\hline inv & 6.91 & 4.39 & 0.70 & 0.83 & -0.34 \\
& $(0.099)$ & $(0.007)$ & $(0.006)$ & $(0.004)$ & $(0.100)$ \\
\hline $\mathrm{n}$ & 0.64 & 0.40 & 0.70 & 0.83 & -0.27 \\
& $(0.009)$ & $(0.001)$ & $(0.006)$ & $(0.004)$ & $(0.101)$ \\
\hline $\mathrm{k}$ & 0.44 & 0.28 & 0.95 & -0.11 & -0.05 \\
& $(0.007)$ & $(0.001)$ & $(0.001)$ & $(0.004)$ & $(0.055)$ \\
\hline$\hat{c}$ & 1.07 & 0.68 & 0.24 & 0.77 & -0.21 \\
& $(0.014)$ & $(0.003)$ & $(0.009)$ & $(0.002)$ & $(0.077)$ \\
\hline
\end{tabular}

Table 8: Learning Model Low Risk Aversion. Descriptive statistics with coefficient of relative risk aversion is $\phi=2$. Second moments are computed for percentage deviations from HP trend. Skewness is of first-differenced series. $\hat{y}, \hat{c}$ are agents' estimated persistent components of output and consumption. We conduct 50,000 simulations. Standard errors (in parentheses) are computed from 250 sample moments of series, each 200 observations long.

\begin{tabular}{||l|c|c|c|c|c||}
\hline & $\begin{array}{c}\text { standard } \\
\text { deviation }\end{array}$ & $\begin{array}{c}\text { relative std } \\
\text { deviation }\end{array}$ & $\begin{array}{c}\text { First-order } \\
\text { autocorrelation }\end{array}$ & $\begin{array}{c}\text { correlation } \\
\text { with GDP }(\hat{y})\end{array}$ & skewness \\
\hline$\hat{y}$ & 1.51 & 1.00 & 0.78 & 1.00 & -0.37 \\
& $(0.022)$ & $(0.00)$ & $(0.004)$ & $(0.000)$ & $(0.083)$ \\
\hline inv & 5.98 & 3.96 & 0.70 & 0.81 & -0.42 \\
& $(0.085)$ & $(0.007)$ & $(0.006)$ & $(0.004)$ & $(0.097)$ \\
\hline n & 0.54 & 0.36 & 0.66 & 0.81 & -0.22 \\
& $(0.008)$ & $(0.001)$ & $(0.006)$ & $(0.004)$ & $(0.088)$ \\
\hline k & 0.39 & 0.26 & 0.95 & -0.15 & -0.03 \\
& $(0.006)$ & $(0.001)$ & $(0.001)$ & $(0.004)$ & $(0.055)$ \\
\hline$\hat{c}$ & 1.09 & 0.72 & 0.30 & 0.82 & -0.20 \\
& $(0.014)$ & $(0.003)$ & $(0.009)$ & $(0.001)$ & $(0.077)$ \\
\hline
\end{tabular}

Table 9: Active Learning Model. Learning model descriptive statistics in model where planner takes into account effects of policy choices on learning. Second moments are computed for percentage deviations from HP trend. Skewness is of first-differenced series. $\hat{y}, \hat{c}$ are agents' estimated persistent components of output and consumption. The coefficient of relative risk aversion is $\phi=4$. We conduct 50,000 simulations. Standard errors (in parentheses) are computed from 250 sample moments of series, each 200 observations long. 


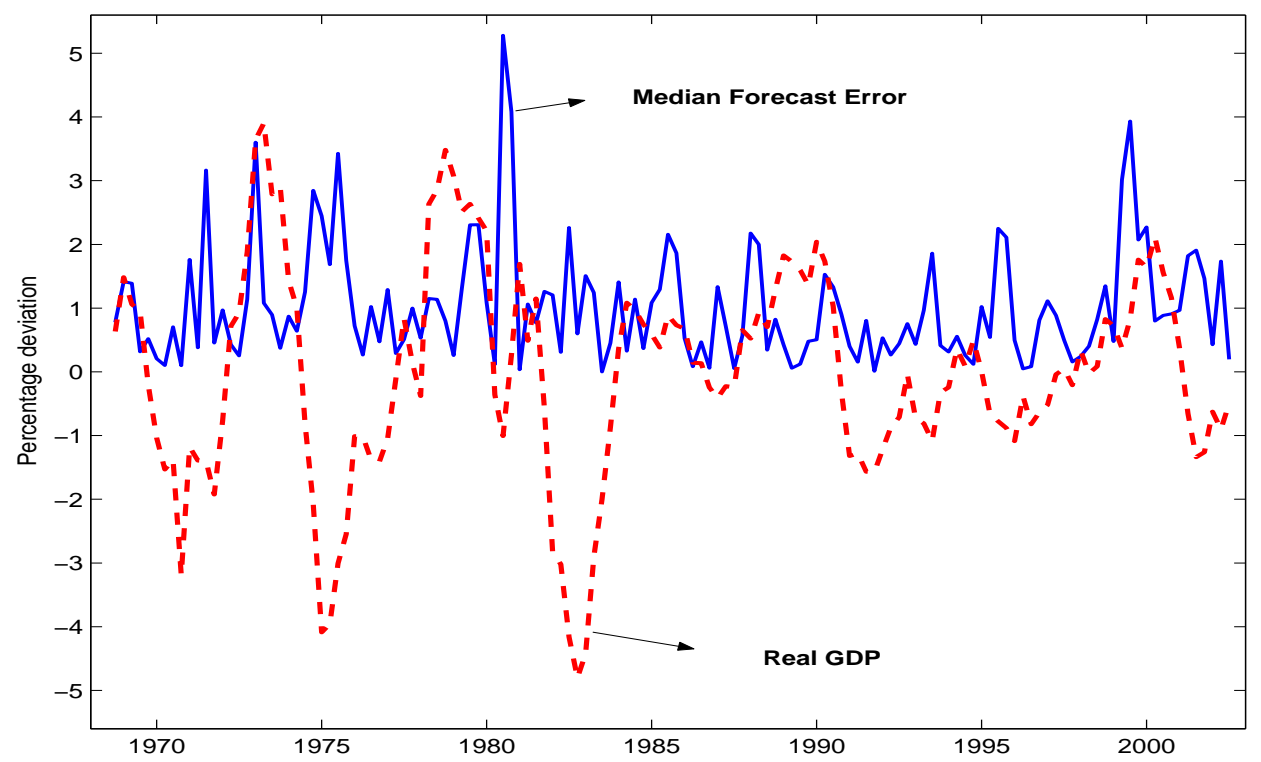

Figure 1: Real GDP in percentage deviations from trend and one quarter ahead median absolute forecast error.

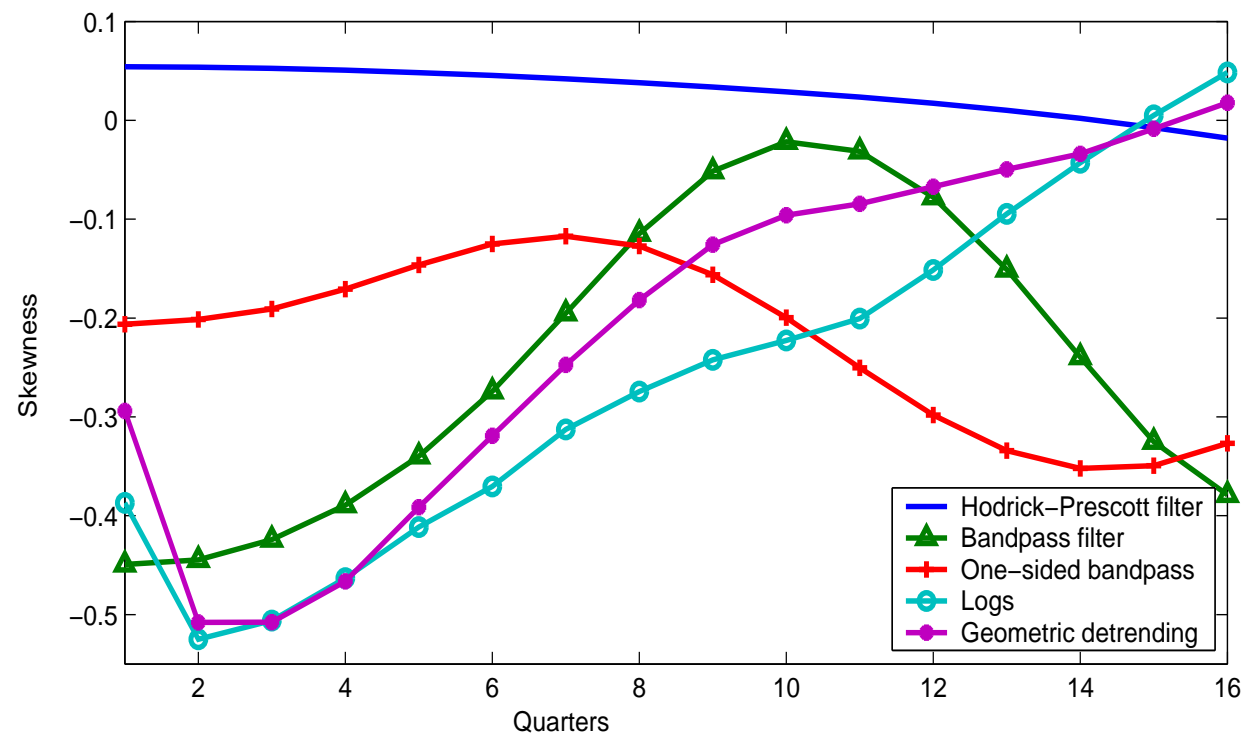

Figure 2: Skewness of $N$-Period Changes in GDP Data for Different Detrending Methods. 


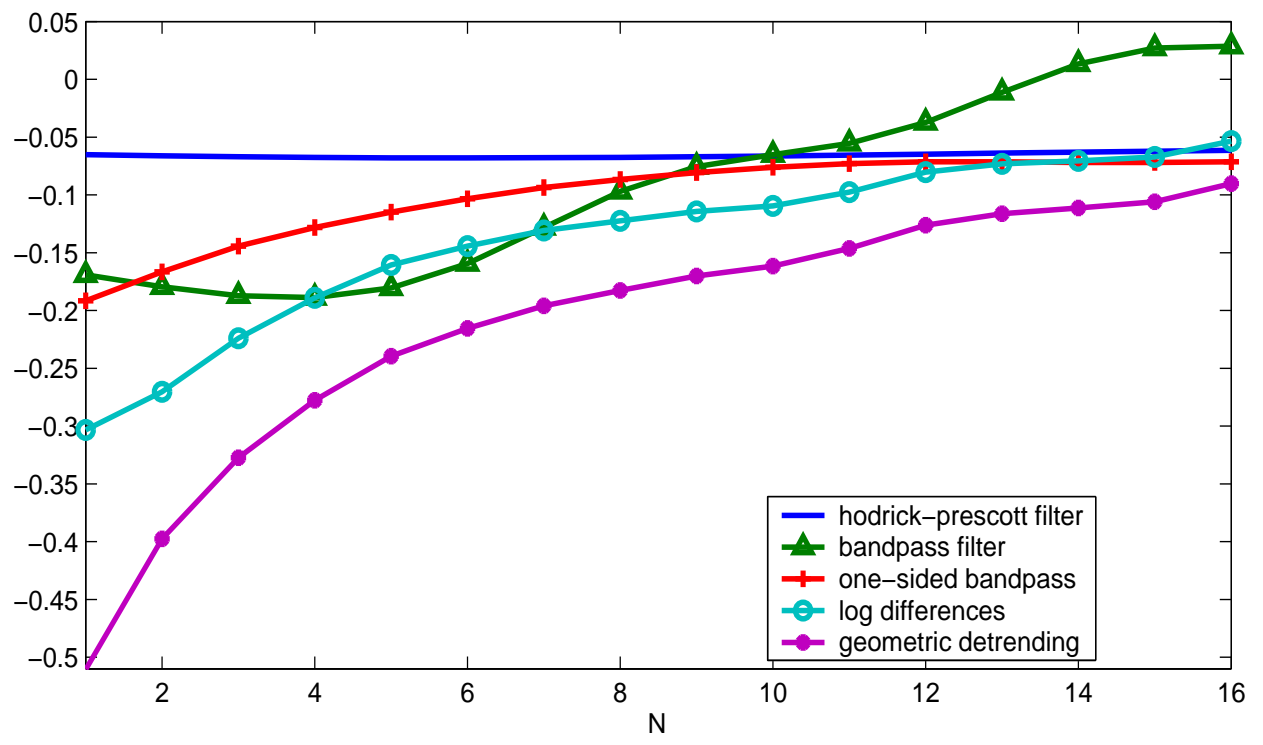

Figure 3: Skewness of $N$-Period Changes in $y_{t}$ in Learning Model for Different Detrending Methods. skewness of $\left(y_{t}-y_{t-N}\right)$, where $y_{t}$ is log of real GDP per capita.

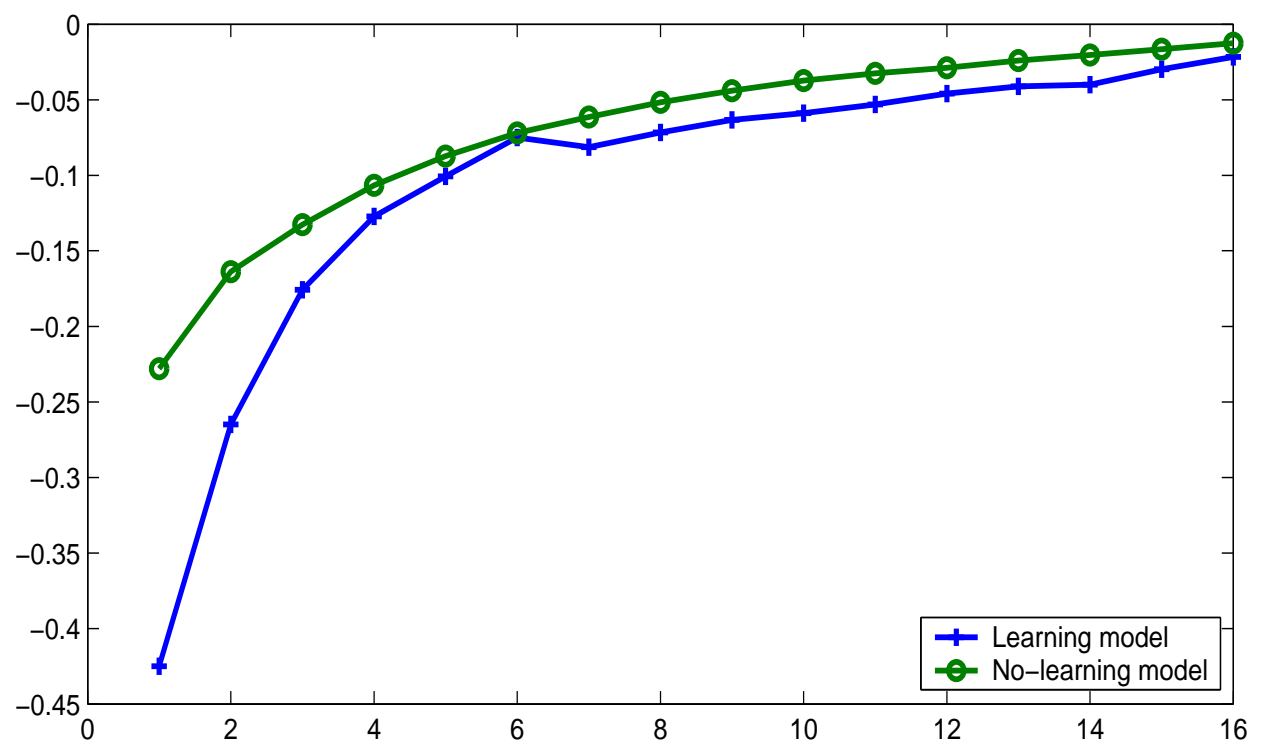

Figure 4: Skewness of $N$-Period Changes in Learning and No-Learning Model. skewness of $\left(y_{t}-y_{t-N}\right)$, where $y_{t}$ is $\log$ of real GDP per capita. 


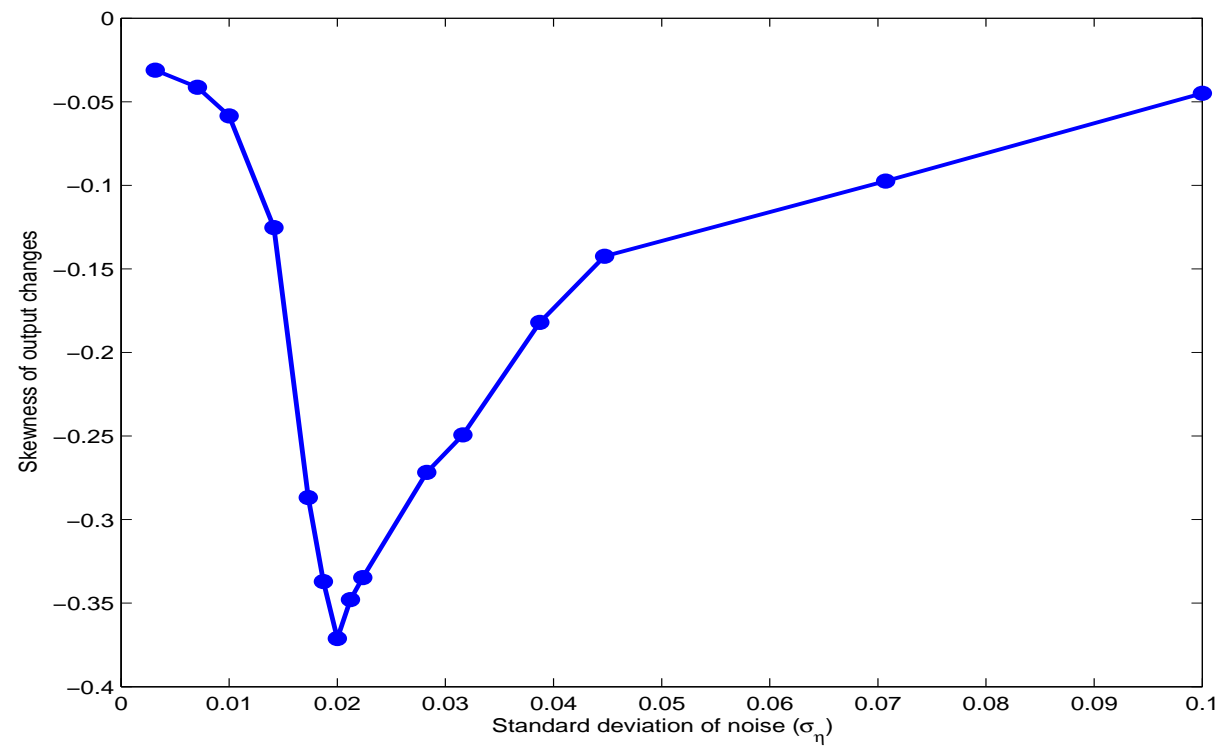

Figure 5: Skewness of output changes $(\Delta \hat{y})$ as the standard deviation of noise $\left(\sigma_{\eta}\right)$ varies. 